\title{
Türkiye'de Saptanan Kompleks Rekombinant HIV-1 CRF06_cpx Alttipinin Moleküler Karakterizasyonu
}

\author{
Molecular Characterization of Complex Recombinant HIV-1 \\ CRF06_cpx Subtype Detected in Turkey
}

\author{
Murat SAYAN ${ }^{1}$, Figen KAPTAN ${ }^{2}$, Bahar ÖRMEN ${ }^{2}$, Nesrin TÜRKER ${ }^{2}$ \\ ${ }^{1}$ Kocaeli Üniversitesi Tıp Fakültesi Hastanesi, Merkez Laboratuvarı, PCR Ünitesi, Kocaeli. \\ ${ }^{1}$ Kocaeli University Medical School Hospital, Central Laboratory, PCR Unit, Kocaeli, Turkey. \\ 2 İzmir Atatürk Eğitim ve Araştırma Hastanesi, Enfeksiyon Hastalıkları ve Klinik Mikrobiyoloji Kliniği, İzmir. \\ ${ }^{2}$ Izmir Ataturk Training and Research Hospital, Infectious Diseases and Clinical Microbiology Clinic, Izmir, Turkey.
}

Geliş Tarihi (Received): 26.04.2013 • Kabul Ediliş Tarihi (Accepted): 13.06.2013

\section{ÖZET}

Dünya çapındaki HIV enfeksiyonlarının önemli ölçüde nedeni HIV-1 genotipinin $M$ grubudur. Günümüzde HIV-1 M grubunun dokuz alttipi (A, B, C, D, F, G, H, J, K) ve 50 kadar tanımlanmış dolaşan rekombinant formu (CRF) bulunmaktadır. HIV-1 CRF, bireyleri enfekte eden en az iki farklı alttipin rekombinasyonu ile ortaya çıkmaktadır. Rekombinasyon, üç ya da daha fazla alttip/CRF içeriyorsa "cpx (complex)" tanımlaması yapılmakta, ancak alttip kompozisyonu ifade edilmemektedir. Bu çalışmada, ülkemizde ilk kez saptanan CRF06_cpx ile enfekte HIV-1 pozitif evli bir çift sunulmuştur. İzmir'de, oral kandidoz ve zona nedeniyle hastaneye başvuran 39 yaşındaki erkek hastada, anti-HIV pozitif, CD4 ${ }^{+} \mathrm{T}$ lenfosit sayısı 21 hücre/mm³ ve HIV-1 RNA yükü 56.380 kopya/ml olarak saptanmıştır. 1996-2002 yılları arasında, Suudi Arabistan'da çalışmak amaçlı bulunan hasta, o dönemde aralarında Afrika kökenlilerin de bulunduğu farklı partnerlerle korunmasız, heteroseksüel ilişki tanımlamaktadır. Yapılan taramada, hastanın 37 yaşındaki eşi de anti-HIV yönünden pozitif bulunmuş; $C D 4^{+} T$ lenfosit sayısı 122 hücre $/ \mathrm{mm}^{3}$ olarak saptanmış, ancak başlangıç plazma HIV-1 RNA düzeyi PCR internal kontrol hatası nedeniyle belirlenememiştir. Hastalardan izole edilen HIV-1 pol geni bölgesi, alttip, rekombinasyon ve ilaç direnci mutasyonları yönünden analiz edilmiştir. Filogenetik analiz "neighbore-joining" yöntemiyle yapılmış ve suşların alttipi CRF06_cpx olarak saptanmıştır. HIV-1 rekombinasyon analizine göre erkek hastada HIV-1 grup M alttip $G, A$, D ve $B$ segmentleri, kadın hastada ise $G, K, A, F$ ve $D$ segmentleri belirlenmiştir. HIV-1 ilaç direnci analizlerine göre her iki hastada, HIV-1 genomunda, L10I + L33F ile proteaz inhibitörü (PI) mutasyonları ve sadece erkek hastada K219N ile nükleozid ters transkriptaz inhibitörü (NRTI) mutasyonu saptanmıştır. Sonuç olarak HIV-1 ile ilişkili moleküler epidemiyolojik çalışmalar, CRF'lerin global yayılımının izlenmesinde ve aşı geliştirme çalışmalarında önem taşımaktadır. Öte yandan, antiretroviral naif bireylerde HIV-1 
primer direnç mutasyonlarının bulunması, antiretroviral direnç analizinin HIV-1 enfeksiyonu yönetiminin bir parçası olması gerektiğini göstermektedir.

Anahtar sözcükler: HIV-1; pol geni; rekombinant alttip; CRF06_cpx, Türkiye.

\section{ABSTRACT}

A major proportion of the global HIV infections is caused by group M of HIV-1 genotype and to date approximately nine subtypes (A, B, C, D, F, G, H, J, K) and 50 circulating recombinant forms (CRFs) have been recognized. Recombinants between different HIV-1 group $M$ subtypes are designated as CRF. The extension 'cpx', for complex, is given if the CRF consists of contributions from three or more different subtypes but the composition of the subtype is not given. The objective of this study was to present, for the first time an HIV-1 positive married couple infected with CRF06_cpx subtype in Izmir, Turkey. A 39-year-old male patient who admitted to hospital with the complaints of oral candidiasis and zona, was found to be anti-HIV positive. CD4 ${ }^{+}$T lymphocyte count was 21 cells $/ \mathrm{mm}^{3}$ and plasma HIV-1 RNA level was $56.380 \mathrm{copies} / \mathrm{ml}$. He reported unprotected heterosexual contact with multiple partners including African women during his stay in Saudi Arabia between 1996 and 2002. After his diagnosis, his 37-yearold wife was screened for HIV infection and she was also found anti-HIV positive, with $\mathrm{CD}^{+} \mathrm{T}$ cell count of 122 cells $/ \mathrm{mm}^{3}$. However, her results of basal plasma HIV-1 RNA could not be obtained because of an internal control error. HIV-1 strains were analysed for subtyping, recombination and drug resistance mutations with pol gene region sequencing. HIV-1 sequences were subtyped as CRF06_cpx after phylogenetic analysis using neighbore-joining method. According to the recombination analysis, HIV-1 pol gene regions consisted of group $M$ subtype $G, A, D$, and $B$ in the male patient and $G K, A, F$, and $D$ in the female patient. While L10I + L33F mutation associated with protease inhibitor (PI) resistance was detected in both of the patients, $\mathrm{K} 219 \mathrm{~N}$ mutation associated with nucleoside reverse transcriptase inhibitor (NRTI) resistance was detected only in the male patient. In conclusion, HIV-1 molecular epidemiology studies are important tools for tracking transmission patterns and the spread of CRF. Global monitoring of CRF subtypes is also important to supply data for HIV vaccine development studies. On the other hand, the detection of HIV-1 primary resistance mutations in antiretroviral naive patients suggested that the resistance testing should be an integral part of the management of HIV infection.

Key words: HIV-1; pol gene; recombinant subtype; CRF06_cpx; Turkey.

\section{Giriş}

Günümüzde yaklaşık 33.3 milyon insan HIV ile enfektedir ${ }^{1}$. HIV sınıflama sistemi 1990’lı yılların sonuna doğru birçok yeni izolatın karakterinin ortaya çıkarılmasıyla kesinleşmiştir. Morfolojik ve biyolojik olarak birbirine benzeyen, ancak zarf glikoproteinlerinde ve diğer antijenik epitoplarındaki farklılaşma nedeniyle günümüzde HIV, HIV-1 ve HIV-2 olmak üzere iki genotipte sınıflandırılmaktadır. HIV-1, M (main ya da major), N (new ya da non-M, non-O), O (outlier) ve P (alfabetik sıra) olmak üzere dört alt grupta tanımlanmaktadır. Dünya çapındaki enfeksiyonların \%95'inden sorumlu tutulan HIV-1 M grubu dokuz alttipe ayrılmakta (A, B, C, D, F, G, H, J, K) ve bunlardan A ve F'nin sırasıyla A1-A5 ve F1, F2 olmak üzere alt-alttipleri bulunmaktadır. Alttiplerin yanında HIV-1 grup M'nin altında dolaşan rekombinant formlar (CRF) ve özgün rekombinant formlar (URF) olmak üzere iki rekombinant form tipi tanımlanmaktadır². Önceleri HIV-1 alttipi olarak 
tanımlanan E ve I, günümüzde CRF içinde yer almaktadır. Her CRF, bir referans numarası ve rekombinasyonu oluşturan alttiplerle tanımlanır. Rekombinasyon üç ya da daha fazla alttip/CRF içeriyorsa "complex" anlamında "cpx" tanımlaması yapılmakta, ancak alttip kompozisyonu ifade edilmemektedir ${ }^{1}$. Sayısı sürekli değişmekle birlikte günümüzde 50 ayrı HIV-1 CRF alttipi tanımlanmış olup, bunların 12'si cpx alttipidir. HIV-1 CRF cpx alttipleri, bölgelere ve ülkelere göre belirli bir coğrafi dağılım göstermektedir ${ }^{1}$.

Ülkemizde ilk kez 1985 yılında bildirilen HIV/AIDS olgusu, günümüzde Sağlık Bakanlığı'nın Ekim 1985-Haziran 2012 yılları arasındaki HIV/AIDS sürveyans verilerine göre 5744 sayısına ulaşmıştır ${ }^{3,4}$. Ülkemizde HIV-1 CRF olgu bildirimleri oldukça günceldir ve yapılan çalışmalara göre ülkemizde CRF01_AE, CRF02_AG, CRF03_AB, CRF08_BC ve CRF12_BF alttipleri dolaşımda bulunmaktadır ${ }^{4-8}$. Bu raporda, ülkemizde ilk kez saptanan bir kompleks rekombinant HIV-1 alttipi; CRF06_cpx sunulmaktadır.

\section{OLGU SUNUMU}

Oral kandidoz ve zona nedeniyle hastaneye başvuran 39 yaşındaki erkek hastanın (IY, İzmir), yapılan tetkiklerinde anti-HIV pozitif ve CD4 ${ }^{+}$T lenfosit sayısı 21 hücre $/ \mathrm{mm}^{3}$ bulundu. Başlangıç plazma HIV-1 RNA düzeyi 56.380 kopya/ml (Abbott HIV-1 Kit, M 2000RT Instrument, Abbott Molecular Inc, ABD) olarak belirlenen hastada, serum

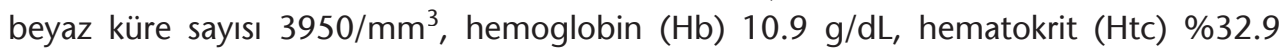
ve trombosit sayısı $176.000 / \mathrm{mm}^{3}$ olarak saptandı. Hastanın rutin biyokimyasal değerleri normal olup, hepatit $\mathrm{B}$, hepatit $\mathrm{C}$ ve TORCH grubu yönünden naif bulundu. Öz geçmişinde, klinik ve laboratuvar olarak tüberküloz bulgusuna rastlanmadı. Çiftçilikle uğraşan ve damar içi ilaç kullanımı, kan veya kan ürünü transfüzyonu ve organ/doku nakli öyküsü bulunmayan hasta, 1996-2002 yılları arasında Suudi Arabistan'da çalışma amaçlı bulunduğunu ve o dönemde aralarında Afrika kökenlilerin de bulunduğu farklı partnerlerle korunmasız, heteroseksüel ilişkiye girdiğini ifade etti. Yapılan taramada hastanın 37 yaşındaki eşi (ZY, İzmir) de anti-HIV yönünden pozitif bulundu ve $C D 4^{+} \mathrm{T}$ lenfosit sayısı 122 hücre/mm³ olarak saptandı. Başlangıç plazma HIV-1 RNA düzeyi, PCR internal kontrol hatası nedeniyle belirlenemedi. Kadın hastanın beyaz küre sayısı 3650/ $\mathrm{mm}^{3}, \mathrm{Hb}: 12.7 \mathrm{~g} / \mathrm{dL}, \mathrm{Htc}$ \%36.6 ve trombosit sayısı $154.000 / \mathrm{mm}^{3}$ olup, rutin biyokimyasal değerleri normal; hepatit $\mathrm{B}$, hepatit $\mathrm{C}$ ve TORCH grubu yönünden naif olduğu tespit edildi. Antiretroviral tedavinin ilk ayında plazma HIV-1 RNA düzeyi 68 kopya/ml olarak saptandı. Servikal lenfadenopatisi (sağ) bulunan hastada ince iğne aspirasyon biyopsisine göre reaktif lenf nodu tanımlandı. Öz geçmişinde, klinik ve laboratuvar olarak tüberküloz bulgusuna rastlanmadı. Hastalarda HIV-1 enfeksiyonu tanısı, "European AIDS Clinical Society (EACS)" kılavuzuna ${ }^{9}$ göre yapıldı ve klinik evreleri CDC (Centers for Diseases Control and Prevention) sınıflamasına göre erkek hastada B3, kadın hastada ise A3 olarak tanımlandı.

Hastalara antiretroviral (ART) tedavi başlamadan önce HIV-1 ilaç direnci analizleri yapıldı. Tedavi öncesi alınan EDTA'lı kan örnekleri hemen santrifüj edilerek, plazma numunesi alikotlandı ve çalışma gününe kadar $-80^{\circ} \mathrm{C}^{\prime}$ de saklandı. Hastalarda tek- 
rarlı olarak pozitif saptanan anti-HIV-1/2 antikor sonuçları (HIV 1/2 Enhanced Assay, Siemens/Bayer Advia Centaur XP, Almanya) Western blot yöntemiyle (DiaPro, HIV-1 LIA, Diagnostic Bioprobes Srl, İtalya) doğrulandı. Anti-HIV-1/2 antikor ve doğrulama testleri sırasında hastaların kimliği gizlendi ve numuneler yeniden verilen kodla çalışıldı.

\section{HIV-1 pol Geni Dizi Analizi}

HIV-1 pol geni dizilemesinde, ters transkriptaz (RT) ve proteaz bölgeleri için The French ANRS (National Agency for AIDS Research, http://hivfrenchresistance.org/) AC11 Direnç Grubu'nun PCR ve dizileme algoritmasından yararlanıldı. HIV-1 integraz bölgesi için PCR ve dizi primerleri tasarlandı. Kullanılan primerler; RT için dış primerler [M]3: 5'-agtaggacctacacctgtca-3' ve MJ4: 5'-ctgttagtgctttggttcctct-3'], iç primerler [( 600 bç), A(35): 5'-ttggttgcactttaaattttcccattagtcctatt-3' ve NE1(35) 5'-cctactaacttctgtatgtcattgacagtccagct-3'] ve dizileme primeri [A(20): $5^{\prime}$-attttcccattagtcctatt-3'] şeklindeydi. Proteaz için dış primer olarak 5'prot1 (5'-taattttttagggaagatctggccttcc-3') ve 3'prot1 (5'-gcaaatactggagtattgtatggattttcagg- $\left.3^{\prime}\right)$, iç $(\sim 400$ bç) ve dizileme primerleri olarak 5'prot2 (5'-tcagagcagaccagagccaacagcccca-3') ve $3^{\prime}$ prot2 (5'-aatgcttttatttttcttctgtcaatggc-3') kullanıldı. Integraz için kullanılan dış primerler; Int F1 (5'- ttgcaggattcaggatcagaag- $3^{\prime}$ ) ve Int R1 (5'-atgaatactgccatttgtact- $\left.3^{\prime}\right)$, iç primerler ( 370 bç); Int F2 (5'-gatctacctgtcatgggtgcc-3') ve Int R2 (5'-tccgcttgctcccttacctg-3') olup, dizileme primeri 5'-gaaatagtagccagctgtgata-3' şeklindeydi.

HIV-1 cDNA sentezi, "Euroscript RT" enziminin kullanıldığı "One step RT qPCR MasterMix" kiti (Eurogentec, Belçika) ile gerçekleştirildi. PCR ürünleri, DNA "Engine peltier" termal döngü platformunda (BioRad Laboratories, $\mathrm{ABD}$ ), $95^{\circ} \mathrm{C}^{\prime} \mathrm{de} 10 \mathrm{dk}$. ön denatürasyon, 45 döngü $95^{\circ} \mathrm{C}^{\prime}$ de $45 \mathrm{sn}, 55^{\circ} \mathrm{C}^{\prime}$ de 45 sn ve $72^{\circ} \mathrm{C}^{\prime}$ de 45 sn koşullarında elde edildi. Primerler, PCR için $0.2 \mathrm{uM}$, dizileme için $0.3 \mathrm{uM}$ final konsantrasyonunda kullanıldı. Tüm PCR ürünleri "High Pure PCR Product Purification Kit" (Roche Diagnostics $\mathrm{GmbH}$, Almanya) ile saflaştırıldı ve ürünler "Beckman Coulter CEQ 8000" platformunda (CEQ 8000 Genetic Analysis System v9, Beckman Coulter Inc, ABD), "DYEnamic ET Terminator Cycle Sequencing Kit" (Amersham Pharmacia Biotech Inc, ABD) kullanılarak dizilendi. Direkt dizileme için kullanılan PCR protokolü; 35 döngü $95^{\circ} \mathrm{C}^{\prime}$ de 20 sn, $50^{\circ} \mathrm{C}^{\prime}$ de 25 sn ve finalde $60^{\circ} \mathrm{C}^{\prime}$ de $2 \mathrm{dk}$ olarak gerçekleşti. Elektroferogramlar "Vector NTI v5.1" (InforMax, Invitrogen, ABD) programı aracılığıyla elde edildi.

\section{HIV-1 Alttiplendirmesi, Rekombinasyon ve "Bootscan" Analizi}

HIV-1 alttipi, "neighbore-joining" yöntemi ile filogenetik olarak analiz edildi. Bu amaçla HIV-1 pol geni RT (kodon 41 - 238), proteaz (kodon 1 - 99) ve integraz (kodon 62-180) kangalları dizilendi. Elde edilen diziler "CLC Sequence Viewer 6.8.1" (CLC bio A/S, Danimarka) programında 1298 baz çift (bç)'lik eşit uzunlukta hizalandı. Filogenetik ağaç, "CLC Sequence Viewer 6.8.1" programı kullanılarak oluşturuldu ve "bootstrap" değeri 1000 olarak alındı (Şekil 1). 


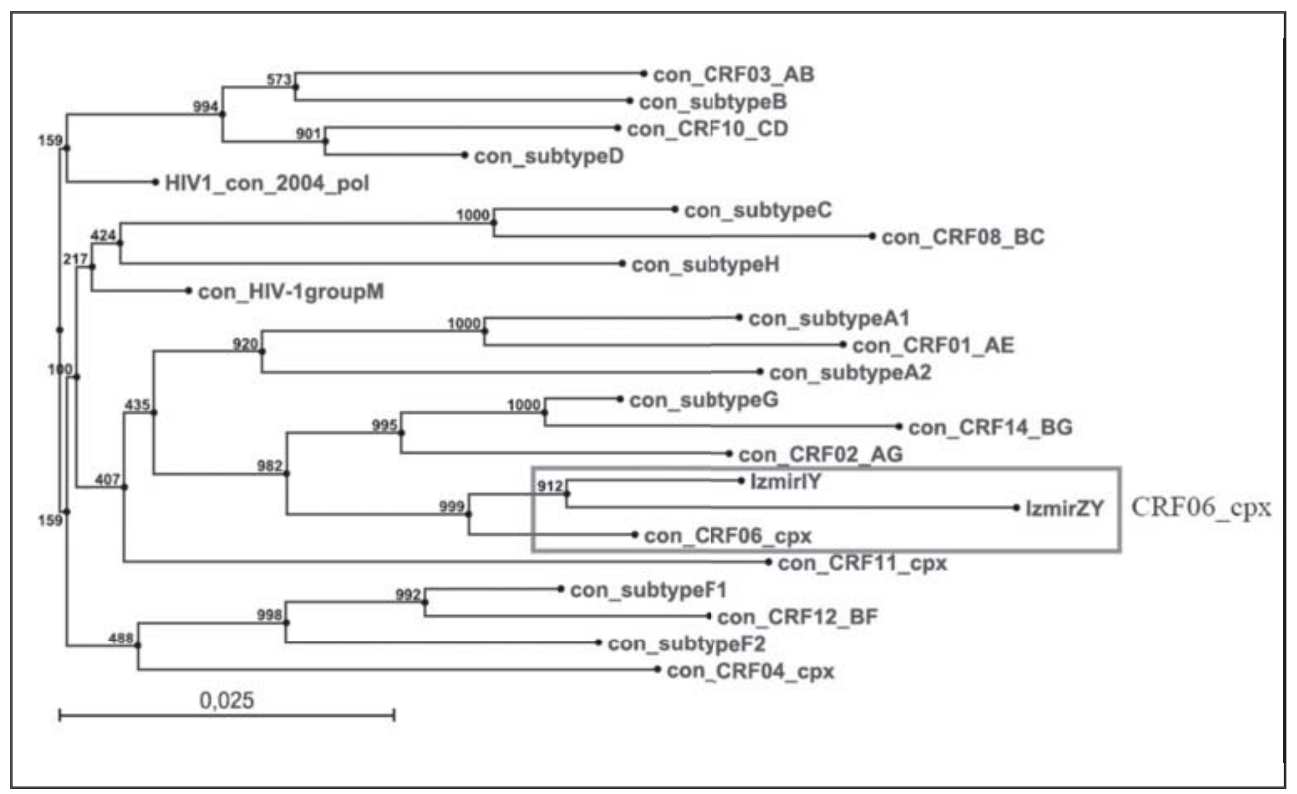

Şekil 1. HIV-1 alttip CRF06_cpx kökenlerinin filogenetik analizi [Filogenetik ağaç, HIV-1 pol geni RT (kodon 41-238), proteaz (kodon 1-99) ve integraz (kodon 62-180) kangalları dizilenerek (1298 bp) ve "neighbore-joining" metodu kullanılarak oluşturuldu. "Bootstrap" değeri 1000 olarak seçildi. Filogenetik ağacın oluşturulmasında "CLC Sequence Viewer 6.8.1" (CLC bio A/S, Aarhus, Danimarka) programı kullanıldı. HIV-1 konsensus (con) referans dizileri Los Alamos National Laboratory (LANL, hiv.lanl.gov) veri tabanından sağlandı].

Rekombinasyon analizinde REGA HIV-1/2 alttiplendirme programı (bioafrica.net, v2.0) kullanıldı. Bu programda, benzeri alttiplendirme programlarından farklı olarak, referans setlerinde HIV-1 grup $M$ alttipleri dışında rekombinant referans diziler (CRF01_ AE, CRF02_AG, CRF03_AB, CRF04_cpx, CRF05_DF, CRF06_cpx, CRF07_BC, CRF08_BC, CRF10_CD, CRF11_cpx, CRF12_BF, CRF13_cpx ve CRF14_BG) kullanmakta ve filogenetik metotlar aracılığıyla rekombinasyon ve "bootscan" analizi yapılabilmektedir (http:// www.bioafrica.net/subtypetool/html/). Bootscan analiziyle elde edilen "bootscan cluster support" oranı, 1 değeri üzerinden ele alınmakta ve bu değerden uzaklaşıldıkça HIV-1 alttipi, rekombinantlaşmaktadır. Ayrıca, bootscan analiziyle HIV-1 alttip segmentleri, incelenen genom bölgesinde nükleotid pozisyonlarına göre tanımlanabilmektedir.

\section{Antiretroviral ilaç Direnci Mutasyon Analizi}

Antiretroviral ilaç direnci mutasyonlarının analizinde HIVdb-Stanford Üniversitesi genotipik direnç değerlendirme (hivdb.stanford.edu) programı kullanıldı. Hastalardan izole edilen HIV-1 suşları, filogenetik analiz sonucunda CRF06_cpx olarak tanımlandı (Şekil 1). Yapılan HIV-1 rekombinasyon analizine göre erkek hastada HIV-1 grup M alttip G, A, D ve B segmentleri, kadın hastada ise $G, K, A, F$ ve $D$ segmentleri belirlendi. HIV-1 ilaç direnci analizlerine göre her iki hastada HIV-1 genomunda L10I + L33F ile proteaz inhibitörü (PI) mutasyonları ve sadece erkek hastada K219N ile nükleozid RT inhibitörü 
(NRTI) mutasyonu saptandı. Hastalarda HIV-1 genomunda integraz inhibitörü mutasyonları saptanmadı (Tablo 1). HIV-1 ilaç direnci analiz sonuçlarına göre tenofovir (300 mg/gün) + emtrisitabin (200 mg/gün) / darunavir (400 mg/gün) + ritonavir (100 mg/ gün) ile yüksek aktif antiretroviral tedavi (HAART) başlanan hastalara Mycobacterium avium kompleks profilaksisi için azitromisin, Pneumocystis carinii profilaksisi için trimetoprim/sülfametoksazol ve kandida profilaksisi için flukonazol verildi. Hastalardan izole edilen HIV-1 CRF06_cpx nükleotid dizi bilgileri (proteaz bölgesi) GenBank'a yüklendi ve erişim numaraları (KC306402 ve KC306403) alındı. Diğer HIV-1 bölge dizilerinin GenBank'a yüklenmesi çalışması halen devam etmektedir.

\section{TARTIŞMA}

Yapılan çalışmalar, ülkemizde HIV-1 alttip CRF'lerin bulunduğunu ve alttiplerin Batı Orta Afrika, Orta Doğu ve Kuzey Afrika (CRF02_AG), Doğu Avrupa ve Orta Asya (CRF03_ $A B)$, Güney Amerika (CRF12_BF) ve Güneydoğu Asya, Doğu Asya ve Orta Afrika kaynaklı (CRF01_AE) olduğunu göstermektedir ${ }^{4,8,10}$. Çalışmamızda elde edilen filogenetik analiz

\begin{tabular}{|c|c|c|c|}
\hline & & Erkek hasta & Kadın hasta \\
\hline \multicolumn{4}{|l|}{ RT kangalı } \\
\hline \multirow[t]{2}{*}{ NRTI } & Mutasyon & $\mathrm{K} 219 \mathrm{~N}$ & ND \\
\hline & Direnç durumu & $\begin{array}{l}\text { 3TC, FTC } \rightarrow \text { Duyarlı } \\
\text { ABC, AZT, d4T, ddl, TDF } \rightarrow \\
\text { Zayıf dirençli }\end{array}$ & $\begin{array}{l}3 \mathrm{TC}, \mathrm{FTC}, \mathrm{ABC}, \mathrm{AZT}, \mathrm{d} 4 \mathrm{~T} \text {, ddl, } \\
\text { TDF } \rightarrow \text { Duyarlı }\end{array}$ \\
\hline \multirow[t]{2}{*}{ NNRTI } & Mutasyon & Saptanmadı & Saptanmadı \\
\hline & Direnç durumu & EFV, ETR, NVP, RPV $\rightarrow$ Duyarlı & EFV, ETR, NVP, RPV $\rightarrow$ Duyarlı \\
\hline \multicolumn{4}{|c|}{ Proteaz kangalı } \\
\hline \multirow[t]{2}{*}{ PI } & Mutasyon & $\mathrm{L} 10 \mathrm{I}+\mathrm{L33F}$ & $\mathrm{L} 10 \mathrm{I}+\mathrm{L} 33 \mathrm{~F}$ \\
\hline & Direnç durumu & $\begin{array}{l}\text { ATV, DRV, IDV, LPV, SQV, TPV } \\
\rightarrow \text { Duyarlı } \\
\text { FPV/r, NFV } \rightarrow \text { Zayıf dirençli }\end{array}$ & $\begin{array}{l}\text { ATV, DRV, IDV, LPV, SQV, TPV } \\
\rightarrow \text { Duyarlı } \\
\text { FPV/r, NFV } \rightarrow \text { Zayıf dirençli }\end{array}$ \\
\hline \multicolumn{4}{|c|}{ İntegraz } \\
\hline \multicolumn{4}{|l|}{ kangalı } \\
\hline \multirow[t]{2}{*}{ INI } & Mutasyon & Saptanmadı & Saptanmadı \\
\hline & Direnç durumu & RAL, EVG, DTG $\rightarrow$ Duyarlı & RAL, EVG, DTG $\rightarrow$ Duyarlı \\
\hline \multicolumn{4}{|c|}{$\begin{array}{l}\text { *Antiretroviral ilaç direnci mutasyon analizinde HIVdb-Stanford Üniversitesi genotipik direnç değerlendirme } \\
\text { (http://hivdb.stanford.edu/) algoritması kullanılmıştır. } \\
\text { 3TC: Lamivudin; ABC: Abakavir; ATV: Atazanavir; AZT: Zidovudin; d4T: Stavudin; ddl: Didanozin; DRV: Darunavir; } \\
\text { DTG: Dolutegravir; EFV: Efavirenz; ETR: Etravirin; EVG: Elvitegravir; FPV/r: Fosamprenavir/ritonavir; FTC: Emtristabin; } \\
\text { IDV: Indinavir; INI: Integraz inhibitörleri. LPV: Lopinavir; NFV: Nelfinavir; NRTI: Nükleozid RT inhibitöleri; } \\
\text { NNRTI: Non-nükleozid RT inhibitörleri; NVP: Nevirapin; PI: Proteaz inhibitörleri; RAL: Raltegravir; RPV: Rilpivirin; } \\
\text { RT: Ters transkriptaz; SQV: Sakinavir; TDF: Tenofovir; TPV: Tipranavir. }\end{array}$} \\
\hline
\end{tabular}


bulguları, HIV-1 CRF06_cpx kökenlerinin de ülkemizde bulunduğunu ortaya koymuştur (Şekil 1). Klinik etkileri tam olarak aydınlatılamamış olan CRF'ler, gerek global ölçekte prevalanslarının artması, gerekse HIV-1 alttiplerini giderek karmaşıklaştırmaları nedeniyle önem kazanmaktadır ${ }^{1}$.

Illk kez 2002 yılında, Montavon ve arkadaşları ${ }^{11}$ tarafından, Senegal ve Mali'li iki hastada saptanan HIV-1 CRF06_cpx kökeninin, tam genoma yakın (7944 bç) dizi analizine göre A, G, J ve $K$ segmentlerini içerdiği anlaşılmıştır. Imamichi ve arkadaşları ${ }^{12} 2009$ yılında, Mali'de yaptıkları bir çalışmada, iki hastada saptadıkları CRF06_cpx HIV-1 alttipinin env geni dizilerinde $\mathrm{G}$, A ve J alttip segmentlerinin bulunduğunu göstermişlerdir. Bizim çalışmamızda, HIV-1 pol geni dizilerinin rekombinasyon analizi sonunda, erkek hastada CRF06_cpx alttip kompozisyonunda HIV-1 alttip G, A, D ve B segmentlerinin, kadın hastada ise $G, K, A, F$ ve $D$ segmentlerinin bulunduğu belirlenmiştir. Buna göre ülkemizde saptadığımız HIV-1 CRF06_cpx alttiplerinde varyasyon geliştiği düşünülebilir. Ayrıca, çalışmamızda elde edilen "bootscan cluster support" değerleri, kadın hastada (0.385) erkek hastaya göre (0.5) daha fazla HIV-1 segment yapısının olduğunu göstermektedir. Diğer yandan, neighbore-joining metodu kullanılarak hazırlanan filogenetik ağaca göre erkek ve kadın hastaya ait HIV-1 CRF06_cpx alttiplerinin birbirlerine olan farklı evrimsel konum uzunlukları HIV-1 segment varyasyonu nedeniyle olabilir (Şekil 1). Bütün bu bulguların tam genom ya da tam genoma yakın dizi analizleriyle doğrulanması yararlı olabilir. Öte yandan CRF06_cpx alttipi sıklıkla Batı/Orta Afrika (Mali, Senegal, Burkina Faso, Nijer, Gana, Fildişi Sahili ve Nijerya) ve Estonya'dan bildirilmekte, ancak son yıllarda Fransa, İtalya, İspanya, Portekiz ve Avustralya'dan da olgu bildirimleri yapılmaktadır ${ }^{1,12,13}$. Bu çalışmalar HIV-1 CRF06_cpx alttipinin global ölçekte dolaştığını göstermektedir.

HIV-1 ile enfekte bireylerde ART ilaç direnci oluşabilir ve bu direnç bulaştırılabilir ${ }^{14}$. Sunduğumuz çalışmada, olgularda primer HIV-1 ilaç direnci mutasyonları bulunmaktadır. Bir popülasyonda, akut ya da kronik HIV-1 enfeksiyonlarında primer ilaç direnci > $\% 5$ ise, ART direnç testlerinin tedavi naif bireylerde uygulanması gerektiği belirtilmekte$\operatorname{dir}^{15}$. Yirmi Avrupa ülkesinde, yeni tanı almış 2793 HIV-1 ile enfekte bireyde, primer ART ilaç direncini araştıran SPREAD programının sonuçlarına göre, toplam ART ilaç direnci \%8.4 ve NRTI, NNRTI ve PI direnci sırasıyla \%4.7, \%2.3 ve \%2.9 olarak bulunmuştur ${ }^{16}$. Ülkemizde son zamanlarda yapılan çalışmalara göre, primer HIV-1 ilaç direnci \%7.6-11.8 arasındadır ve daha ziyade NRTI grubu ilaçlarla ilişkilidir ${ }^{8,10,17}$. Öte yandan bu çalışmada sunulan HIV-1 integraz inhibitörleri analizi, ülkemiz için bir ilk olma özelliğindedir. Sonuç olarak, HIV-1'in ülkemize giriş ve yayılma yollarını anlamak ve enfeksiyonlarını kontrol edebilmek için HIV-1 alttiplendirme çalışmalarına gereksinim vardır. Global ölçekte artış gösteren HIV-1 CRF'lerin izlenmesi, aşı geliştirme çabaları için önemli olabilir. Bu çalışmada, ART naif bireylerde primer direnç mutasyonlarının bulunmuş olması, tedavi öncesinde ART direnci analizlerinin yapılması gerektiğini göstermektedir. 


\section{TEŞEKKÜR}

Bu araştırma, Kocaeli Üniversitesi Klinik Araştırma Etik Kurulu tarafından değerlendirilmiş ve KOU KAEK 2013/45 protokolü ile (Karar No: 6/6) onay almıştır.

\section{KAYNAKLAR}

1. Hemelaar J. The origin and diversity of the HIV-1 pandemic. Trends Mol Med 2011; 25(5): 679-89.

2. Frankenberry KD, Galli A, Nikolaitchik $O$, et al. Mechanisms and factors that influence high frequency retroviral recombination. Viruses 2011; 3(9): 1650-80.

3. Alp E, Bozkurt I, Doğanay M. Epidemiological and clinical characteristics of HIV/AIDS patients followed-up in Cappadocia region: 18 years experience. Mikrobiyol Bul 2011; 45(1): 125-36.

4. Sayan M, Kumbasar Karaosmanoğlu H, Mete B, et al. Molecular epidemiological analysis of HIV-1 pol gene sequences isolated in Istanbul, Turkey. Mikrobiyol Bul 2013; 47(1): 87-97.

5. Akhan S, Sayan M. HIV and acute HBV infection: first case report from Kocaeli, Turkey. $22^{\text {nd }}$ Conference of the Asian Pacific Association for the Study of the Liver (APASL), 16-19 February 2012, Taipei, Taiwan.

6. Yılmaz G, Midilli K, İstanbullu A, Türkoğlu S, Çalangu S, Altaş K. Türkiye'de ilk kez saptanan rekombinant HIV-1 ile infekte iki olgu. 2. Ulusal AIDS Sempozyumu, 2-5 Aralık 2004, İzmir.

7. Sayan M, Kaya S. The first detected HIV-1 recombinant strain in Turkey: CRF08_BC. Mikrobiyol Bul 2013; 47(2): 339-45.

8. Sayan M, Willke A, Ozgunes N, Sargın F. HIV-1 subtypes and primary antiretroviral resistance mutations in antiretroviral therapy naive HIV-1 infected individuals in Turkey. Jpn J Infect Dis 2013; 66(4): 306-11.

9. European AIDS Clinical Society (EACS). Guidelines, Version 6 - October 2011. http://www.eacsociety.org/ Portals/0/files/pdf\%20files/EACSGuidelines-v6.0-English.pdf

10. Üser ÜY, Sayan M, İnan D. Antalya bölgesinde HIV-1 subtip dağılımı ve antiretroviral ilaç direnci mutasyonları. Klinik HIV/AIDS Sempozyumu 2012, 23- 25 Kasım 2012, Kapadokya.

11. Montavon C, Toure-Kane C, Nkengasong JN, et al. CRF06-cpx: a new circulating recombinant form of HIV-1 in West Africa involving subtypes A, G, K, and J. J Acquir Immune Defic Syndr 2002; 29(5): 522-30.

12. Imamichi $H$, Koita $O$, Dabitao D, et al. Identification and characterization of CRF02_AG, CRF06_cpx, and CRF09_cpx recombinant subtypes in Mali, West Africa. AIDS Res Hum Retroviruses 2009; 25(1): $45-55$.

13. Mamadou S, Vidal N, Montavan, C, et al. Emergence of complex and diverse CRF02-AG/CRF06-cpx recombinant HIV type 1 strains in Niger, West Africa. AIDS Res Hum Retroviruses 2003; 19(1): 77-82.

14. Bennett DE, Camacho RJ, Otelea D, et al. Drug resistance mutations for surveillance of transmitted HIV-1 drug-resistance: 2009 Update. PLoS One 2009; 4: e4724.

15. Sax PE, Islam R, Walensky RP, et al. Should resistance testing be performed for treatment-naive HIV-infected patients? A cost-effectiveness analysis. Clin Infect Dis 2005; 41(9): 1316-23.

16. Vercauteren J, Wensing AM, van de Vijver DA, et al. Transmission of drug-resistant HIV-1 is stabilizing in Europe. J Infect Dis 2009; 200(10): 1503-8.

17. Sayan M, Aydın OA, Mete B, et al. HIV-1 primary drug resistance mutations in antiretroviral therapy naive patients in Istanbul, Turkey. $11^{\text {th }}$ International Congress on Drug Therapy in HIV Infection. 11-15 November 2012, Glasgow, UK. J Int AIDS Soc 2012; 15(Suppl 4): 18181. 